\title{
Behçet's Disease Is Associated with Multiple Sclerosis and Rheumatoid Arthritis: A Korean Population-Based Study
}

\author{
Jin Hyung Jung ${ }^{a}$ Kyung Do Han ${ }^{b}$ Young Bok Lee ${ }^{c}$ Yong Gyu Park ${ }^{d}$ \\ a Department of Biomedicine and Health Science, Graduate School, The Catholic University of Korea, \\ Seoul, South Korea; ${ }^{b}$ Department of Statistics and Actuarial Science, Soongsil University, Seoul, South Korea; \\ 'Department of Dermatology, College of Medicine, The Catholic University of Korea, Seoul, South Korea; \\ ${ }^{\mathrm{d}}$ Department of Biostatistics, College of Medicine, The Catholic University of Korea, Seoul, South Korea
}

\section{Keywords}

Behçet's disease · Rheumatoid arthritis · Multiple sclerosis .

Nationwide population study

\begin{abstract}
Background: No epidemiologic study has previously reported on the associations among Behçet's disease (BD) and autoimmune disorders. Objectives: To investigate the association between $\mathrm{BD}$ and the autoimmune disorders multiple sclerosis and rheumatoid arthritis. Methods: Medical records of patients newly diagnosed with BD $(n=6,214)$ in 2012 2017 were analyzed using data entered into a large, nationwide database from 2007 to 2017. An age- and sex-matched control population of individuals without BD was sampled at a ratio of controls:BD cases of 3:1 $(n=18,642)$. Both cohorts were analyzed for the presence of multiple sclerosis or rheumatoid arthritis within a minimum of 5 years prior to their BD diagnosis. Results: Patients with BD had significantly higher odds ratios (ORs) for multiple sclerosis $(8.85$ [95\% Cl 2.3633.17]) and rheumatoid arthritis (4.62 [95\% Cl 3.35-6.35]) than the control group after adjustment for diabetes melli-
\end{abstract}

Y.B.L. and Y.G.P. contributed equally to this work.

karger@karger.com www.karger.com/drm

Karger $\stackrel{\text { ! }}{\text { - }}$

GOPEN ACCESS
(C) 2021 The Author(s)

Published by S. Karger AG, Basel

This is an Open Access article licensed under the Creative Commons Attribution-NonCommercial-4.0 International License (CC BY-NC) (http://www.karger.com/Services/OpenAccessLicense), applicable to the online version of the article only. Usage and distribution for commercial purposes requires written permission. tus, hypertension, and dyslipidemia. BD patients aged $<40$ years had a higher proportion of rheumatoid arthritis (OR $23.91,95 \% \mathrm{Cl} 5.50-103.9)$ than older patients (OR 3.96, 95\% $\mathrm{Cl}$ 2.83-5.54). Conclusion: Our results suggest that BD is associated with multiple sclerosis and rheumatoid arthritis.

(c) 2021 The Author(s)

Published by S. Karger AG, Basel

\section{Introduction}

Behçet's disease (BD), synonymous with Adamantiades-Behçet disease and Behçet's syndrome, is a rare systemic inflammatory disease ranging from 0.1 per 100,000 population in the USA [1] to 664 per 100,000 population estimated for northern Jordan [2]. A meta-analysis found the prevalence of BD to be 10.3 (95\% confidence interval [CI] 6.1-17.7) per 100,000 population globally [3]. In 2017, a large population-based study was conducted to investigate the prevalence and mortality rate of $\mathrm{BD}$ in South Korea between 2006 and 2015. The study found the annual incidence rate to be 3.97 per 100,000 person-years, which was much higher than in other countries [4].

Yong Gyu Park

Department of Biostatistics, College of Medicine

The Catholic University of Korea, 222, Banpo-daero

Seocho-gu, Seoul 137-701 (South Korea)

ygpark@catholic.ac.kr

Department of Dermatology, Uijeongbu St. Mary's Hospital

College of Medicine, The Catholic University of Korea

271 Chunbo Street, Uijeongbu 07345 (South Korea)

lyb80@ catholic.ac.kr 


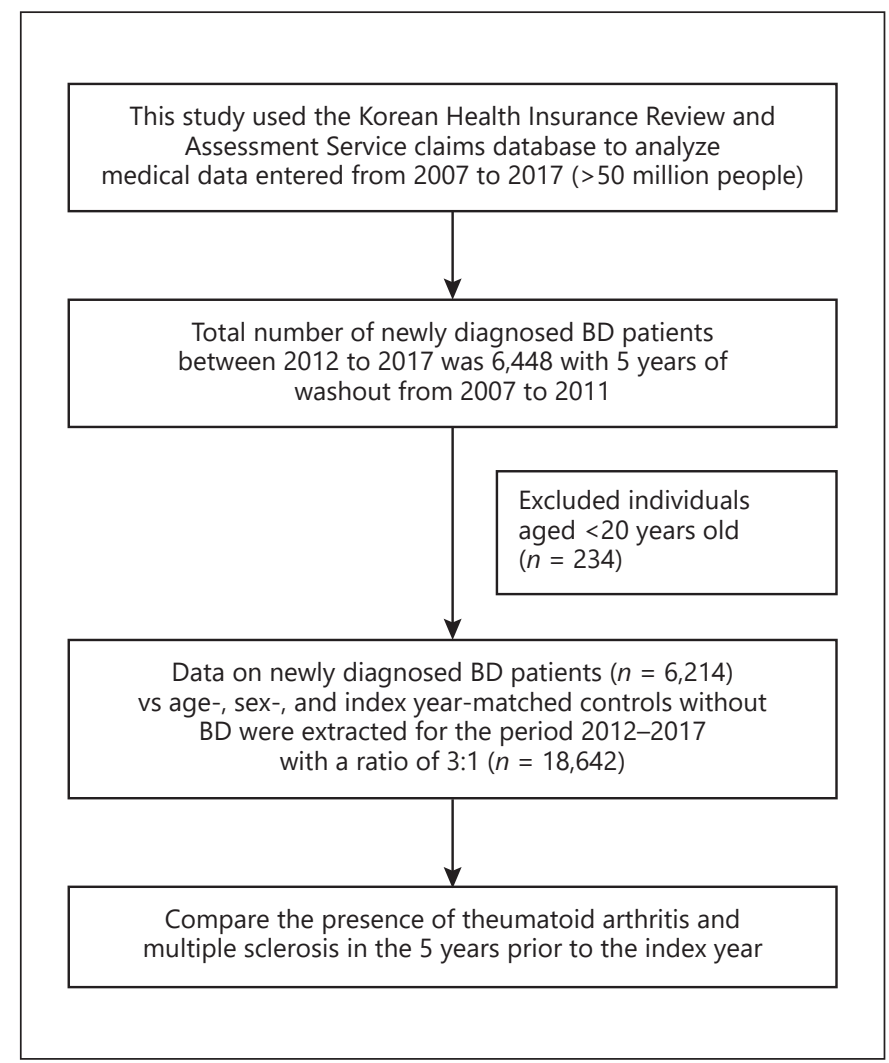

Fig. 1. Flowchart of materials and methods. BD, Behçet's disease.

$\mathrm{BD}$ is classified as an autoinflammatory disorder because of the absence of pathogenic autoimmune $\mathrm{T}$ and $\mathrm{B}$ cell responses. Autoinflammatory disorders are characterized by an abnormally increased inflammatory response that is mediated predominantly by the cells and molecules of the innate immune system [5]. The clinical features of BD include oral and genital aphthous ulcers, uveitis, a positive skin pathergy test, papulopustular or acne-like lesions, and arthritis, features which are also observed in other autoinflammatory disorders [6].

Unlike monogenic autoinflammatory disorders, BD is considered a multifactorial or acquired autoimmune disorder. Several genetic factors are suspected to have a pathogenic influence, including the genes encoding human leukocyte antigen (HLA)-B51 [7]. Epigenetic alterations are also reported in patients with BD [8] and environmental factors such as microorganisms [9-11], vitamin $\mathrm{D}$ deficiency $[12,13]$, and smoking [14-19] are associated with $\mathrm{BD}$. BD is considered to be a hybrid of autoinflammatory and autoimmune disorders, or a "mixed-pattern disease" [6]. The strong association of HLA-B51 with BD might explain an adaptive immunity component that is driven by lymphocytes with antigen receptors and has decisive functions in autoimmune disorders [20].

This study investigated the associations of autoimmune disorders, including multiple sclerosis and rheumatoid arthritis, with BD. We used a nationwide, population-based cohort design and data from the Korean National Health Insurance (KNHI) database.

\section{Materials and Methods}

For further details, see the online supplementary material (www.karger.com/doi/10.1159/000514634) and Figure 1.

\section{Results}

\section{Characteristics of the Study Population}

Of the 6,214 patients, 3,855 were female $(62.0 \%)$ and 2,359 were male $(38.0 \%)$. Mean age was $46.9 \pm 13.2$ years, with most participants (54.8\%) aged between 40 and 59 years. Because we extracted a control group matched for age, sex, and year of claim, the characteristics of the control group were the same as those of the $\mathrm{BD}$ group (Table 1).

\section{Positive Associations between Autoimmune Disorders and $B D$}

The analysis of claims data entered from 2007 to 2017 at least 5 years prior to baseline showed a proportion for multiple sclerosis $(0.14 \%)$ and rheumatoid arthritis $(1.63 \%)$ in the $\mathrm{BD}$ group that was significantly higher than in the control group ( 0.02 and $0.34 \%$, respectively). The comorbid diseases diabetes mellitus, hypertension, and dyslipidemia were significantly higher in the BD group (Table 1).

Odds ratios (ORs) for multiple sclerosis and rheumatoid arthritis in the BD group were 9 (95\% CI 2.44-33.24) and 4.78 (95\% CI 3.49-6.55), respectively. Increased ORs for multiple sclerosis $(8.85$; 95\% CI 2.36-33.17) and rheumatoid arthritis (4.62; 95\% CI 3.35-6.35) in the BD group were consistent after adjustment for other comorbid diseases (Table 2).

\section{Subgroup Analysis}

The ORs for multiple sclerosis and rheumatoid arthritis were further analyzed according to age, sex, and the presence of diabetes mellitus, hypertension, or dyslipidemia (Fig. 2). 
Table 1. Demographics of study population

\begin{tabular}{|c|c|c|c|}
\hline & $\begin{array}{l}\text { Controls } \\
(n=18,642)\end{array}$ & $\begin{array}{l}\text { Patients with Behçet's } \\
\text { disease } \\
(n=6,214)\end{array}$ & $p$ value \\
\hline Sex & & & 1 \\
\hline Male & $7,077(38.0)$ & $2,359(38.0)$ & \\
\hline Female & $11,565(62.0)$ & $3,855(62.0)$ & \\
\hline Calendar year & & & 1 \\
\hline 2012 & $2,823(15.1)$ & $941(15.1)$ & \\
\hline 2013 & $2,871(15.4)$ & $957(15.4)$ & \\
\hline 2014 & $2,946(15.8)$ & $982(15.8)$ & \\
\hline 2015 & $3,318(17.8)$ & $1,106(17.8)$ & \\
\hline 2016 & $3,573(19.2)$ & $1,191(19.2)$ & \\
\hline 2017 & $3,111(16.7)$ & $1,037(16.7)$ & \\
\hline Age group & $46.9 \pm 13.2$ & $46.9 \pm 13.2$ & 1 \\
\hline 20-39 years & $5,466(29.3)$ & $1,822(29.3)$ & \\
\hline $40-59$ years & $10,221(54.8)$ & $3,407(54.8)$ & \\
\hline$\geq 60$ years & 2,955 (15.9) & $985(15.9)$ & \\
\hline \multicolumn{4}{|l|}{ Comorbidities } \\
\hline Diabetes mellitus & $1,126(6.0)$ & $458(7.4)$ & 0.0002 \\
\hline Hypertension & $3,886(20.9)$ & $1,533(24.7)$ & $<0.0001$ \\
\hline Dyslipidemia & $3,859(20.7)$ & $1,459(23.5)$ & $<0.0001$ \\
\hline \multicolumn{4}{|l|}{ Autoimmune disorders } \\
\hline Multiple sclerosis & $3(0.02)$ & $9(0.14)$ & $<0.0001$ \\
\hline Rheumatoid arthritis & $64(0.34)$ & $101(1.63)$ & $<0.0001$ \\
\hline
\end{tabular}

Fig. 2. Subgroup analysis by age, sex, and the presence of comorbid diseases. Odds ratios for multiple sclerosis and rheumatoid arthritis in patients with Behçet's disease. ${ }^{*}$ Not available. Odds ratios were not estimated because the number of events was too small for subgroup analyses.

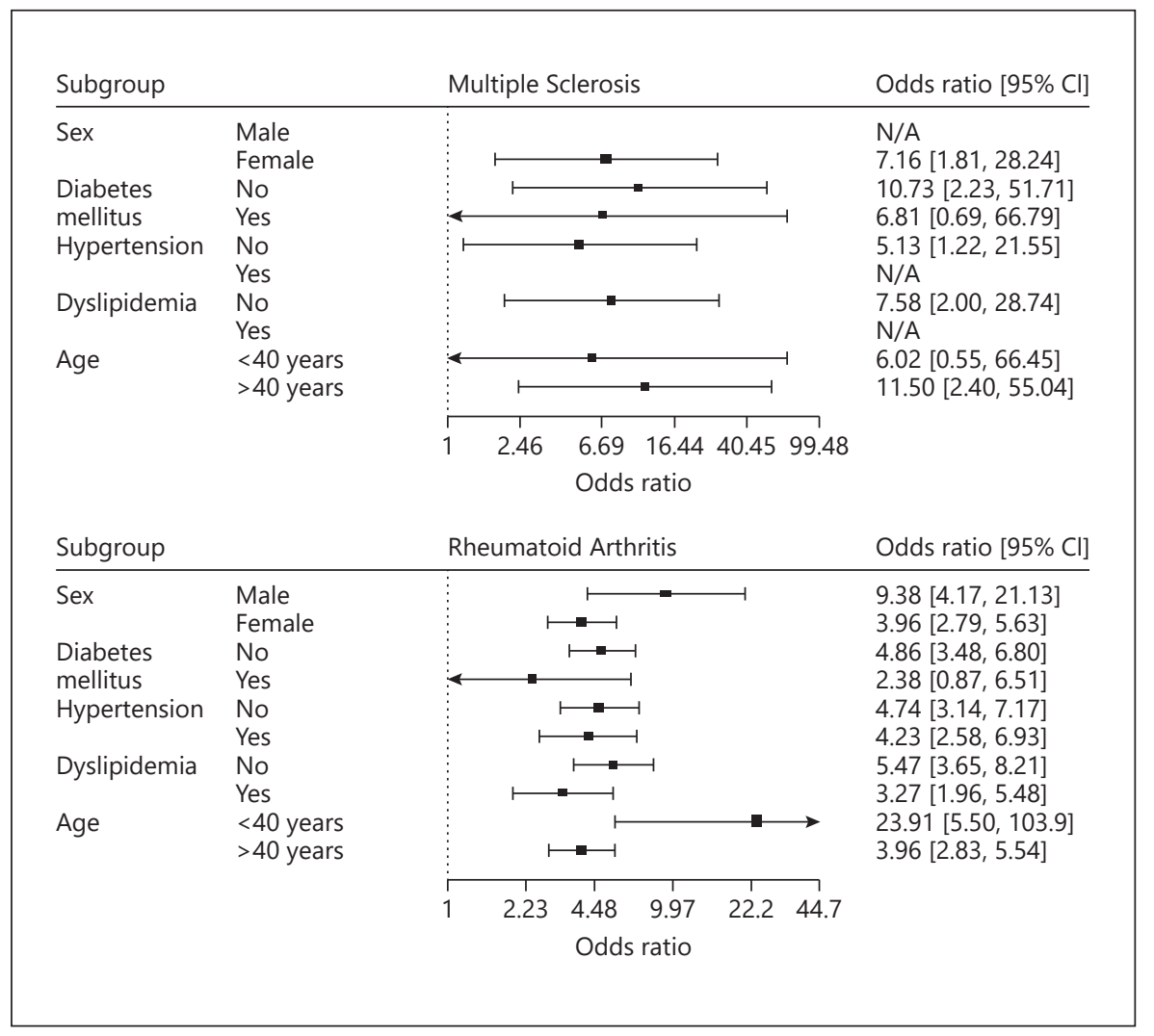


Table 2. Odds ratios for multiple sclerosis and rheumatoid arthritis in patients with Behçet's disease.

\begin{tabular}{lcl}
\hline $\begin{array}{l}\text { Autoimmune and } \\
\text { autoinflammatory } \\
\text { disorders }\end{array}$ & \multicolumn{2}{l}{ Odds ratio (95\% confidence interval) } \\
\cline { 2 - 3 } & Model 1 & Model 2 \\
\hline $\begin{array}{l}\text { Multiple sclerosis } \\
\text { Rheumatoid arthritis }\end{array}$ & $9.78(2.44-33.24)$ & $8.85(2.36-33.17)$ \\
\hline
\end{tabular}

The reference was the control group. A multivariate logistic regression model of comorbid diseases was used for Model 2. Model 1, Univariate. Model 2, Multivariate with adjustment for diabetes mellitus, hypertension, and dyslipidemia and other autoimmune disorders (multiple sclerosis or rheumatoid arthritis).

In the $\mathrm{BD}$ group, 9 patients had multiple sclerosis and there were 3 in the control group. The increased proportion of multiple sclerosis in BD patients persisted after subgroup analyses. The OR for rheumatoid arthritis in the $\mathrm{BD}$ group was higher in males than in females. $\mathrm{Pa}$ tients in the $\mathrm{BD}$ group without comorbid diseases had a higher OR for rheumatoid arthritis than patients with comorbid disease. Patients aged $<40$ years (OR 23.91; 95\% CI 5.50-103.9) had a higher proportion of rheumatoid arthritis than older patients (OR 3.96; 95\% CI 2.83-5.54).

\section{Discussion}

This study used a nationwide cohort database to show increased ORs for multiple sclerosis and rheumatoid arthritis in $\mathrm{BD}$ patients compared to controls.

The incidence of BD in Korea is reported to be 4.0 per 100,000 person-years [4]. Rates of comorbid metabolic diseases such as diabetes mellitus, hypertension, and dyslipidemia are significantly higher in patients with $\mathrm{BD}$ in Korea than in controls without BD [4]. Although inflammatory bowel disease as a comorbidity is suggested to be increased in patients with $\mathrm{BD}$, the association of rheumatoid arthritis and multiple sclerosis with BD has not been previously reported.

Some neuro-BD patients are reported to have clinical and laboratory features resembling multiple sclerosis rather than neuro-BD [23-25]. Neuro-BD mimics multiple sclerosis in some aspects, including a high occurrence in young individuals, a relapsing-remitting or progressive course, the perivascular infiltration of inflammatory cells, hyperintense lesions on T2-weighted magnetic resonance imaging (MRI), abnormal evoked potentials, and a treatment response to corticosteroids and immu-

Behçet's Disease and Autoimmune Diseases nosuppressant drugs [25]. However, parenchymal involvement is typically seen in the basal ganglia and diencephalon in neuro-BD and in periventricular and whitematter lesions in multiple sclerosis. The hygiene hypothesis states that multiple sclerosis is frequently observed in developed countries. However, neuro-BD is associated with poor hygiene, with an increased chance of exposure to infectious agents [26]. Since the treatments are different for multiple sclerosis and neuro-BD, differentiating neuro-BD from multiple sclerosis is important [23]. Both neuro-BD and multiple sclerosis cause cognitive dysfunctions such as impairments in memory and frontal-lobe executive function. The pathogenic mechanisms underlying the association between $\mathrm{BD}$ and multiple sclerosis have not yet been established; however, several studies have investigated possible mechanisms [26, 27]. According to Oezguen et al. [27], an altered gut microbiota community is implicated in neuro-BD and multiple sclerosis.

The proportion of rheumatoid arthritis is increased in patients with $\mathrm{BD}$; however, the association between rheumatoid arthritis and BD has not been fully established. A case report showed $\mathrm{BD}$ development in a patient with longstanding rheumatoid arthritis [28]. A vitamin D receptor gene polymorphism has been reported in both $\mathrm{BD}$ and rheumatoid arthritis [29, 30]. However, little is known about a possible pathomechanism between the 2 diseases.

This study has several limitations. First, the possibility of misdiagnosis cannot be ruled out. Some patients may have been clinically classified as having multiple sclerosis or rheumatoid arthritis for therapeutic purposes or to gain government support. However, the OR for multiple sclerosis and sero-positive rheumatoid arthritis in $\mathrm{BD}$ patients was significantly higher than in controls and high rates of overlap symptoms were worthy of notice. Second, although multiple sclerosis is diagnosed via spinal tap and MRI findings that are different from neuro-BD, we cannot identify whether the neuro-BD patients were misdiagnosed as having multiple sclerosis. It is difficult to differentiate the MRI findings of neuro-BD and multiple sclerosis. Because the KNHIS does not allow access to the chart review of patients, it was impossible to clarify whether an accurate diagnosis had been made. However, results suggest that neurologic manifestation may appear first in BD patients, and it is possible that the first neurologic symptoms of $\mathrm{BD}$ might mimic clinical manifestation of multiple sclerosis. Third, there was a possibility that arthritis symptoms in BD patients were misdiagnosed as rheumatoid arthritis. However, in this study, 
rheumatoid arthritis with rheumatoid factor positivity (ICD-10 code M05 and rare intractable diseases code V223) was diagnosed by a rheumatologist according to criteria excluding sero-negative rheumatoid arthritis (ICD-10 code M06). Fourth, health-related habits such as smoking status or alcohol consumption were not available in the HIRA database. Health-related habits might influence the incidence of $\mathrm{BD}[14,19,31]$ but the HIRA database does not include this information.

Despite its limitations, this study has several strengths. It was a nation-wide, population-based cohort study. The ORs for rheumatoid arthritis and multiple sclerosis were remarkably high in patients with newly diagnosed $\mathrm{BD}$. We propose that there are indeed increased ORs for these autoimmune disorders in patients with BD. Physicians should be aware of the high proportion of these autoimmune disorders in their patients with $\mathrm{BD}$ and treatment should also take into account common concurrent autoimmune disorders. This study will help to broaden our understanding of BD pathogenesis.

\section{Key Message}

Behçet's disease is associated with multiple sclerosis and rheumatoid arthritis.

\section{Statement of Ethics}

This study was reviewed and approved by the Institutional Review Board at Uijeongbu St. Mary's Hospital, Catholic University of Korea (UC19ZEISI0017) and conducted according to the principles of the Declaration of Helsinki. All identifiable personal information in the medical records was de-identified to comply with the privacy rules of the Health Insurance Portability and Accountability Act. As information used for analyses from the HIRA database was encrypted, anonymized and de-identified, informed consent was not required.

\section{Conflict of Interest Statement}

The authors declare there were no conflicts of interest.

\section{Funding Sources}

There are no funding sources to declare.

\section{Author Contributions}

Y.B.L. and Y.G.P.: study design. J.H.J. and K.D.H.: data collection and analysis. Y.B.L. interpretation of findings and preparation of the manuscript. All authors read and approved the final manuscript.

\section{References}

1 Hirohata T, Kuratsune M, Nomura A, Jimi S. Prevalence of Behçet's syndrome in Hawaii. With particular reference to the comparison of the Japanese in Hawaii and Japan. Hawaii Med J. 1975 Jul;34(7):244-6.

2 Madanat WY, Alawneh KM, Smadi MM, Saadeh SS, Omari MM, Bani Hani AB, et al. The prevalence of Behçet's disease in the north of Jordan: a hospital-based epidemiological survey. Clin Exp Rheumatol. 2017 Nov-Dec;35(6 Suppl 108):51-4.

3 Maldini C, Druce K, Basu N, LaValley MP, Mahr A. Exploring the variability in Behçet's disease prevalence: a meta-analytical approach. Rheumatology (Oxford). 2018 Jan; 57(1):185-95.

4 Lee YB, Lee SY, Choi JY, Lee JH, Chae HS, Kim JW, et al. Incidence, prevalence, and mortality of Adamantiades-Behçet's disease in Korea: a nationwide, population-based study (2006-2015). J Eur Acad Dermatol Venereol. 2018 Jun;32(6):999-1003.

5 Kastner DL, Aksentijevich I, Goldbach-Mansky R. Autoinflammatory disease reloaded: a clinical perspective. Cell. 2010 Mar;140(6): 784-90.
6 Gül A. Pathogenesis of Behçet's disease: autoinflammatory features and beyond. Semin Immunopathol. 2015 Jul;37(4):413-8.

7 Na SJ, Kang MJ, Yu DS, Han KD, Lee JH, Park YG, et al. Cancer risk in patients with Behçet disease: A nationwide population-based dynamic cohort study from Korea. J Am Acad Dermatol. 2018 Mar;78(3):464-70.e2.

8 Alipour S, Nouri M, Sakhinia E, Samadi N, Roshanravan N, Ghavami A, et al. Epigenetic alterations in chronic disease focusing on Behçet's disease: review [Review]. Biomed Pharmacother. 2017 Jul;91:526-33.

9 Mumcu G, Inanc N, Yavuz S, Direskeneli H. The role of infectious agents in the pathogenesis, clinical manifestations and treatment strategies in Behçet's disease. Clin Exp Rheumatol. 2007 Jul-Aug;25(4 Suppl 45):S27-33.

10 Kaneko F, Tojo M, Sato M, Isogai E. The role of infectious agents in the pathogenesis of Behçet's disease. Adv Exp Med Biol. 2003;528: 181-3.

11 Direskeneli H. Behçet's disease: infectious aetiology, new autoantigens, and HLA-B51. Ann Rheum Dis. 2001 Nov;60(11):996-1002.
12 Djeraba Z, Benlabidi F, Djaballah-Ider FZ, Medjeber O, Arroul-Lammali A, Belguendouz H, et al. Vitamin D status in Algerian Behçet's disease patients: an immunomodulatory effect on NO pathway. Immunopharmacol Immunotoxicol. 2017 Aug;39(4):243-50.

13 Faezi ST, Ansari N, Paragomi P, Akhlaghi M, Ghanavat M, Davatchi F. Vitamin D deficiency in patients with Behcet's disease. J Diabetes Metab Disord. 2014 Jan;13(1):18.

14 Malek Mahdavi A, Khabbazi A, Yaaghoobian B, Ghojazadeh M, Agamohammadi R, Kheyrollahiyan A, et al. Cigarette smoking and risk of Behcet's disease: A propensity score matching analysis. Mod Rheumatol. 2019 Jul;29(4): 633-9.

15 Özer HT, Günesaçar R, Dinkçi S, Özbalkan Z, Yildiz F, Erken E. The impact of smoking on clinical features of Behçet's disease patients with glutathione S-transferase polymorphisms. Clin Exp Rheumatol. 2012 May-Jun; 30(3 Suppl 72):S14-7.

16 Aramaki K, Kikuchi H, Hirohata S. HLA-B51 and cigarette smoking as risk factors for chronic progressive neurological manifestations in Behçet's disease. Mod Rheumatol. 2007;17(1):81-2. 
17 Kaklamani VG, Tzonou A, Markomichelakis N, Papazoglou S, Kaklamanis PG. The effect of smoking on the clinical features of Adamantiades-Behçet's disease. Adv Exp Med Biol. 2003;528:323-7.

18 Rizvi SW, McGrath H Jr. The therapeutic effect of cigarette smoking on oral/genital aphthosis and other manifestations of Behçet's disease. Clin Exp Rheumatol. 2001 Sep-Oct; 19(5 Suppl 24):S77-8.

19 Soy M, Erken E, Konca K, Ozbek S. Smoking and Behçet's disease. Clin Rheumatol. 2000; 19(6):508-9.

20 McGonagle D, McDermott MF. A proposed classification of the immunological diseases. PLoS Med. 2006 Aug;3(8):e297.

21 Arnett FC, Edworthy SM, Bloch DA, McShane DJ, Fries JF, Cooper NS, et al. The American Rheumatism Association 1987 revised criteria for the classification of rheumatoid arthritis. Arthritis Rheum. 1988 Mar; 31(3):315-24.

22 Aletaha D, Neogi T, Silman AJ, Funovits J, Felson DT, Bingham CO 3rd, et al. 2010 Rheumatoid arthritis classification criteria: an American College of Rheumatology/European League Against Rheumatism collaborative initiative. Arthritis Rheum. 2010 Sep; 62(9):2569-81.
23 Akman-Demir G, Mutlu M, Kiyat-Atamer A, Shugaiv E, Kurtuncu M, Tugal-Tutkun I, et al. Behçet's disease patients with multiple sclerosis-like features: discriminative value of Barkhof criteria. Clin Exp Rheumatol. 2015 NovDec;33(6 Suppl 94):S80-4.

24 Shamim A, Budman CL. A complex case of neuro-Behcet's disease in a patient previously diagnosed with multiple sclerosis: A case report. CNS Spectr. 2011 Apr;16(4):95-8.

25 Ashjazadeh N, Borhani Haghighi A, Samangooie S, Moosavi H. Neuro-Behcet's disease: a masquerader of multiple sclerosis. A prospective study of neurologic manifestations of Behcet's disease in 96 Iranian patients. Exp Mol Pathol. 2003 Feb;74(1):17-22.

26 Pehlivan M, Kürtüncü M, Tüzün E, Shugaiv E, Mutlu M, Eraksoy M, et al. The comparison of socio-economic conditions and personal hygiene habits of neuro-Behçet's disease and multiple sclerosis patients. Int J Hyg Environ Health. 2011 Jul;214(4):335-7.
27 Oezguen N, Yalcinkaya N, Kucukali CI, Dahdouli M, Hollister EB, Luna RA, et al. Microbiota stratification identifies disease-specific alterations in neuro-Behcet's disease and multiple sclerosis. Clin Exp Rheumatol. 2019; 37 Suppl 121(6):58-66.

28 Chang HK, Lee JY. behcet's disease developing in longstanding rheumatoid arthritis. Clin Exp Rheumatol. 2003;21(4 Suppl 30):S56.

29 Karray EF, Ben Dhifallah I, Ben Abdelghani K, Ben Ghorbel I, Khanfir M, Houman H, et al. Associations of vitamin $\mathrm{D}$ receptor gene polymorphisms FokI and BsmI with susceptibility to rheumatoid arthritis and Behçet's disease in Tunisians. Joint Bone Spine. 2012 Mar;79(2):144-8.

30 Tizaoui K, Kaabachi W, Ouled Salah M, Ben Amor A, Hamzaoui A, Hamzaoui K. Vitamin $D$ receptor TaqI and ApaI polymorphisms: a comparative study in patients with Behçet's disease and Rheumatoid arthritis in Tunisian population. Cell Immunol. 2014 Jul;290(1): 66-71.

31 Lee YB, Lee JH, Lee SY, Lee JH, Yu DS, Han $\mathrm{KD}$, et al. Association between smoking and Behçet's disease: a nationwide populationbased study in Korea. J Eur Acad Dermatol Venereol. 2019 Nov;33(11):2114-22. 